\title{
FSH stimulates the expression of the ADAMTS-16 protease in mature human ovarian follicles
}

\author{
Shuping Gao ${ }^{1}$, Christian De Geyter ${ }^{1,2,3}$, K.Kossowska ${ }^{1}$ and Hong Zhang ${ }^{1,2}$ \\ ${ }^{I}$ Department of Research, Women's Hospital, University of Basel, Switzerland, ${ }^{2}$ Department of Obstetrics and Gynecology, \\ University Hospital of Basel, Spitalstrasse 21, CH-4031 Basel, Switzerland \\ ${ }^{3}$ Correspondence address. Tel: +41 61265 9315; Fax: +41 61 265 9194; E-mail: cdegeyter@uhbs.ch
}

\begin{abstract}
We report the characterization of full-length human ADAMTS (a disintegrin and metalloproteinase with thrombospondin motifs)-16, a novel member of the disintegrin and metalloproteinase with thrombospondin motifs (hence ADAMTS) family. ADAMTS-16 is highly expressed both in the kidney and in the ovary, where it is predominantly expressed in the parietal granulosa cells of pre-ovulatory follicles but only slightly expressed in cells of the cumulus oophorus. In fully differentiated luteinizing granulosa cells, follicle-stimulating hormone and forskolin induces expression of ADAMTS-16, suggesting that it is regulated via the cAMP pathway. Luteinizing hormone had a minor effect on the expression of ADAMTS-16. ADAMTS-16 is capable of cleaving $\alpha_{2}$-macroglobulin (MG), a common substrate for proteases, which is present at high concentrations in the follicular fluid of ovarian follicles. These studies provide the first evidence that ADAMTS-16 is an active protease and suggest a physiological role of ADAMTS-16 in ovarian follicles, at least during the pre-ovulatory phase.
\end{abstract}

Keywords: ADAMTS-16/ovulation/FSH/ovarian follicle/ $\alpha_{2}$-macroglobulin

\section{Introduction}

The ADAMTSs (a disintegrin and metalloproteinase with thrombospondin motifs) are a family of 19 structurally related proteases, which are secreted in various organ systems and which can bind to specific proteins of the extracellular matrix (ECM). Since their first description (Kuno et al., 1997) studies on ADAMTS have recently been rapidly expanding, because they have been implicated in a number of diseases including cancer (Coussens et al., 2002). In addition to their involvement in ECM modelling, the ADAMTSs are involved in the functional regulation of a large number of cytokines, hormones, growth factors and proteases. Consequently, various members of the ADAMTS family are involved in the pathogenesis of apparently unrelated diseases such as osteoarthritis (Kevorkian et al., 2004), bleeding disorders (Vazquez et al., 1999), endothelial defects (Zheng et al., 2001) and cancer (e.g. breast cancer, Porter et al., 2004). Additionally, various members of the ADAMTS family play important roles in normal ovarian physiology. It has been demonstrated that ADAMTS- 1 mRNA and protein were induced in granulosa cells of periovulatory follicles by luteinizing hormone $(\mathrm{LH})$ in wild type but not in progesterone receptor knockout mice (PRKO), indicating that ADAMTS- 1 is a transcriptional target of the progesterone receptor around the time of ovulation (Robker et al., 2000; Doyle et al., 2004). Studies in ADAMTS-1 (-/-) knockout mice demonstrated that the number of ovulated oocytes is significantly reduced as compared with heterozygous controls (Shindo et al., 2000; Shozu et al., 2005). The presence of ovulations, albeit significantly reduced, in ADAMTS-1 (-/-) knockout mice and the involvement of other members of the ADAMTS family of proteases in the ovulatory process demonstrates a large degree of redundancy among the various members of this family (Richards et al., 2005).
Two proteases structurally and functionally closely related to ADAMTS-1, ADAMTS-4 and ADAMTS-5 are present in granulosa cells of small ovarian follicles, indicating that various members of the ADAMTS family also have functions beyond ovulation and the formation of the luteal body (Richards et al., 2005).

Searching for novel markers of granulosa cell function, we identified ADAMTS-16 during the analysis of our ovary-specific gene expression database based on its high expression level in the ovary. In this report, novel data concerning both the regulation and the function of ADAMTS-16 in the ovary are presented.

\section{Materials and Methods}

\section{Cloning of human ADAMTS-16 variants and chromosomal location of ADAMTS-16}

OR0021 was identified based on its high level of expression in the ovary in our ovary- enriched gene expression database and OR0021 was found to be identical to ADAMTS-16 (Cal et al., 2002). Searching the GenBank database of human expressed sequence tags (ESTs) with the ADAMTS-16 cDNA sequence, and another EST sequence (GenBank accession no. AK122980) was detected and sequenced; its gene was named ADAMTS-16s. The search of the GenBank database for STSs using ADAMTS-16 as a template revealed that a human STS WI-6822 (accession number G06277) matches 100\% to the nucleotides +941 to +1229 of the ADAMTS-16 sequence. ADAMTS-16 was found to be located on chromosome 5 by using the NCBI Unigen programme. The GenBank accession number for ADAMTS-16s is DQ266047.

Dragon Gene Start Finder was used to predict the transcriptional start site of ADAMTS-16 upstream of the translational initiation codon (ATG). The programme PromotorInspector was used to analyse the genomic sequences at the $5^{\prime}$ end of the ADAMTS-16 gene for putative promotor regions. 


\section{Tissue expression pattern analysis by $R T-P C R$}

In order to determine the expression patterns of ADAMTS-16 mRNA in different human tissues, RT-PCR was performed, using the primers $5^{\prime}$ - AACT CAGCCTGCACGATTCAC $-3^{\prime}$ and $5^{\prime}$ - CAGTGCCCATTCAGGTAGTAC $-3^{\prime}$ on a panel of first-strand cDNAs from various human tissues (Origene, MD, USA). The PCR conditions were as described in the manufacturer's protocol with 30 cycles performed on the $\beta$-actin control employing Taq polymerase.

Microarray data of mouse testis, generated by the GNF Mouse Atlas v2 project (Su et al., 2004), were obtained from the hgFixed database of the UCSC Genome Browser (Karolchik et al., 2003).

\section{Hormonal treatment of ovarian cells in vitro}

Human luteinizing granulosa cells were obtained by follicular aspiration from women undergoing oocyte retrieval for assisted reproduction. The study was approved by the local research ethics committee. The age range of the women was 24-41 years. For each experimental cell culture, the granulosa cells obtained from one to three patients collected during the same day were pooled, enzymatically dispersed with $0.1 \%$ hyaluronidase (Sigma Chemical Co., St Louis, MO, USA) and separated from red blood cells by centrifugation through Ficoll-Paque (Pharmacia Biotech, Sweden). The cells were plated at a density of $2-5 \times 10^{5}$ cells/well on $35 \mathrm{~mm}$ six-well dishes and cultured in Dulbecco's modified Eagle's medium (DMEM) (Gibco) supplemented with $10 \%$ fetal calf serum (FCS; Gibco), $2 \mathrm{mmol} / \mathrm{l} \mathrm{L}$-glutamine and antibiotics (100 IU/ml penicillin and $100 \mu \mathrm{g} / \mathrm{ml}$ streptomycin) at $37^{\circ} \mathrm{C}$ in a $95 \%$ air $-5 \%$ $\mathrm{CO}_{2}$ humidified environment. Cell culture media were changed every other day. On day 7 , the cells were stimulated for $24 \mathrm{~h}$ with forskolin $(10 \mu \mathrm{M})$ or with recombinant human follicle-stimulating hormone $(\mathrm{rhFSH}, 500 \mathrm{ng} / \mathrm{ml}$, Gonal F, Serono, Zug, Switzerland) or with rhLH (100 IU/l, Luveris, Serono). Each experiment was repeated three times.

\section{Fluorescence activated cell sorter and sorting of granulosa cells}

Follicular fluid aspirates containing luteinizing granulosa cells were collected from infertile patients treated with exogenous gonadotrophins for assisted reproduction. The freshly collected clumps of granulosa cells were mechanically dissociated by nylon filters and stored frozen at $-80^{\circ} \mathrm{C}$. After thawing, the isolated granulosa cells were identified by the simultaneous presence of two specific markers, FSH receptor (FSHR) and LH receptor (LHR), on their surface and subsequently sorted using a fluorescence activated cell sorter (FACS). In order to identify and sort granulosa cells, a dual labelling technique was introduced, where granulosa cells were identified as CD3-negative cells, distinguishing them from leukocytes, which are CD3-positive (De Neubourg et al., 1998). The first polyclonal goat antibody rose against a peptide mapping either the FSHR or LHR of human origin (Santa-Cruz Biotechnology). The first antibody was added for $30 \mathrm{~min}$ and kept on ice in the dark. The second antibody was a donkey anti-goat IgG labelled with fluorescence isothiocyanate (FITC) (Santa-Cruz Biotechnology), incubated for $30 \mathrm{~min}$ on ice in the dark. In addition, granulosa cells without the primary antibody were used as a negative control. CD3 anti-leukocyte antibodies were used as a positive control (anti-CD3-APC monoclonal mouse antibodies-Becton Dickinson). The gating for the sorting of FSHR-positive cells was established by performing FACS with isotype control. Sorted cells were cultured in DMEM supplemented with either recombinant FSH $\left(100 \mathrm{ng} / \mathrm{ml}\right.$ or $3 \times 10^{-4} \mathrm{IU} / \mathrm{ml}$, Gonal F; Serono) or recombinant LH $(100 \mathrm{ng} / \mathrm{ml}$, Luveris, Serono $)$ and with 1:50 dilution of $200 \mu \mathrm{g} / \mathrm{ml}$ of anti-FSHR (sc-7798, Santa Cruz Biotechnology) or anti-LHR antibody (sc-25828, Santa Cruz Biotechnology), respectively. As a negative control, granulosa cells were cultured in the presence of both anti-FSHR and anti-LHR antibodies (as above).

\section{Quantitative real-time PCR}

Total RNA was extracted from GCs using a commercially available RNeasy Total RNA kit from Qiagen (Hilden, Germany). The quantity of RNA was assessed by measuring the optical density at A260 nm. Total RNA $(1 \mu \mathrm{g})$ from GCs was reversed transcribed into single strand cDNA using the cDNA synthesis kit (Boehringer Mannheim, Mannheim, Germany). Primers for realtime PCR were synthesized by Microsynth, Balgath, Switzerland: hA16 (forward) 5' AAACTCCTCAGTGGCCCTTTC 3' and R (reversed) 5' CGTAT CATGCCTGACAAGCCT $3^{\prime}$. Power SYBR Green PCR Master Mix
(AB Applied Biosystems) for real-time PCR and TaqMan GAPDH Control Reagent (PE Applied Biosystems) as internal control were used. cDNA was subjected to 40 cycles of real-time PCR amplification carried out using ABI PRISM 7000 Sequence Detector System (AB Applied Biosystems). The difference between the results was assessed statistically with the Mann-Whitney $U$-test.

\section{Plasmid constructs}

Pblue-script-k-Kiaa2029 (ADAMTS-16) was kindly provided by Kazusa DNA Research Institute (Kikuno et al., 2004). Full-length ADAMTS-16 was cloned in-frame into pGEX-4T-2 Vector with Sal I /Not I sites. ADAMTS-16s was generated by PCR and cloned using the primers 5'-CGTGGATCCCATTTCTG-TGGAAGACGC-3' and 5'-CGGGAATTCG CCACTTGCACT GTG TGT TT-3'. The PCR-product was digested with BamHI and EcoRI and cloned in-frame into the EcoRI/BamH I sites of pGEX-4T-1 or pcDNA3-HisC (Invitrogen, Groningen, The Netherlands). All constructs were confirmed by sequencing.

\section{Purification of ADAMTS-16 GST-fusion and His-tagged proteins}

In brief, pGEX-4T-2_ADAMTS-16 and pGEX-4T-1_ADAMTS-16 pep were transformed to DE3 bacteria (BL20). The positive clones were cultured in $250 \mathrm{ml} \mathrm{LB}\left(100 \mathrm{mg} / \mathrm{ml}\right.$ ampicillin) for $3-4 \mathrm{~h}$ at $30^{\circ} \mathrm{C}$ in a shaker until OD.600 $\mathrm{nm}$ reached $0.6-0.8$. Then, IPTG was added to a final concentration of $0.1 \mathrm{mM}$ (final concentration: $350 \mathrm{ng} / \mathrm{ml}$ ), and the bacteria were cultured for an additional $4 \mathrm{~h}$. Cells were collected by centrifugation and the pellets were stored at $-70^{\circ} \mathrm{C}$. Subsequently, the pelleted cells were lysed in $3 \mathrm{ml}$ cold lysis buffer ( $50 \mathrm{mM} \mathrm{Na}_{2} \mathrm{HPO}_{4}$, $\mathrm{pH} 8.0 ; 0.3 \mathrm{M} \mathrm{NaCl} ; 1 \mathrm{mM}$ PMSF with protease inhibitors) containing freshly added lysozyme $(100 \mu \mathrm{g} / \mathrm{ml})$ and sonicated $5 \times 20 \mathrm{~s}$ until the sample cleared and was no longer viscous. Upon centrifugation, samples were boiled at $95^{\circ} \mathrm{C}$ for $5 \mathrm{~min}$ and loaded on $10 \%$ SDS-PAGE. His-tagged proteins were produced by transfection of pcDNA3-Hisc-ADAMTS-16 in HEK293 cells. Protein concentration was determined by BioRad mini kit.

\section{Cleavage of $\alpha_{2}$-macroglobulin}

About $45 \mu \mathrm{l}$ of buffer $\left(100 \mathrm{mM}\right.$ Tris- $\mathrm{HCl}, 20 \mathrm{mM} \mathrm{CaCl}_{2}$ and $200 \mathrm{mM} \mathrm{NaCl}$, $\mathrm{pH} 7.5$ ) were added to $45 \mu \mathrm{l} 50 \%$ GST beads (containing $5 \mathrm{mM}$ Tris, $10 \mathrm{mM}$ $\mathrm{NaCl}, \mathrm{pH} 7.5, \mathrm{GE}$ ) and/or His Bead (Roche). ADAMTS-16 and ADAMTS$16 \mathrm{~s}$ at a concentration of $20 \mathrm{ng} / \mu \mathrm{l}$ were incubated with $5 \mu 1$ of $10 \mathrm{mM} \mathrm{ZnCl} 2$ and $5 \mu \mathrm{l}$ of $100 \mathrm{ng} \alpha_{2}$-macroglobulin (MG) at $37^{\circ} \mathrm{C}$ for $2 \mathrm{~h}$ in $1.5 \mathrm{ml}$ Eppendorf tubes. Subsequently, the products were analysed for total protein by SDS-PAGE on $8-10 \%$ gels followed by staining with Coomassie Brilliant Blue R-250 to analyse for cleavage of MG.

\section{Results}

\section{Molecular cloning of human ADAMTS-16 and its variant ADAMTS-16s}

During the search of our ovarian-rich gene expression database, OR0021 was identified based on its high expression levels in the ovary (see below). This gene has been designated as ADAMTS-16, a member of the family of proteases, jointly denoted as ADAMTS. By screening the EST database, followed by PCR, we identified the full-length cDNA (Fig. 1), including the $3^{\prime}$ sequence, which was missing in an earlier report (Cal et al., 2002). In addition, we identified a novel splicing variant (ABB70405) and termed it ADAMTS-16s for the short splicing form of the ADAMTS-16 transcript (Fig. 1). Sequence analysis revealed that the full-length ADAMTS-16 exhibits the typical ADAMTS modular structure (containing signal sequence, propeptide, metalloproteinase domain, disintegrin-like domain, central TS1 motif, cysteine-rich region and a C-terminal module with several TS1 submotifs) and that ADAMTS-16s encoded an open reading frame of 570 amino acids, containing only the peptidase domain (Fig. 1). Sequencing of AK031314 from NCBI provided an ORF encoding the full-length mouse ADAMTS-16. The human and 


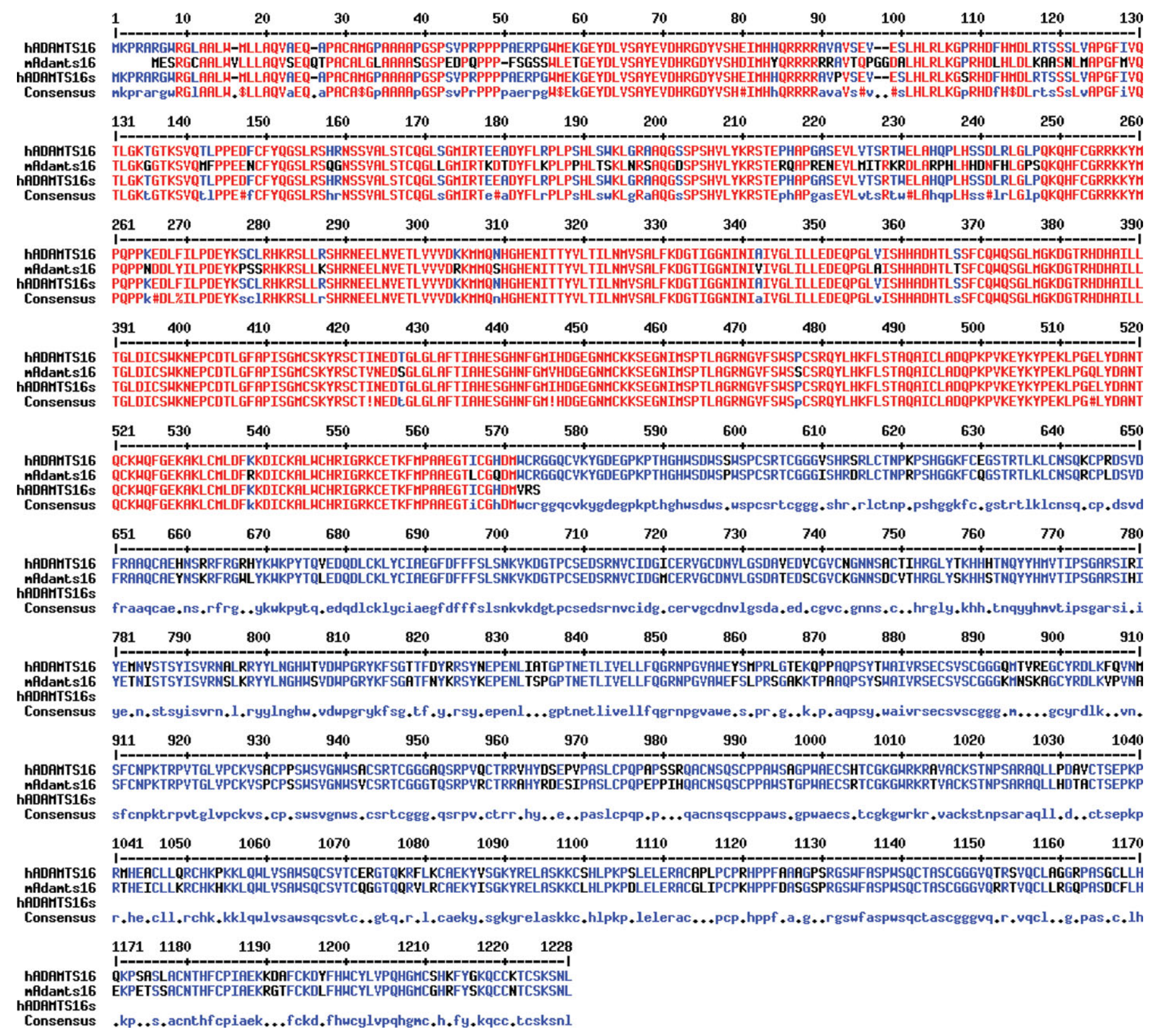

Figure 1: Isolation of cDNAs encoding the human gene ADAMTS-16 and its variant ADAMTS-16s

Alignment of the amino acid sequence of ADAMTS-16 and its splice variant ADAMTS-16s from human and mouse using the multiple alignment programme (Multalin). Letters in red indicate 100\% indentity within 3 sequences, letters in blue are those identical between two sequences, letters in black indicate low consensus value

mouse nucleotide and predicted amino acid sequences have an overall identity of $86 \%$ and $91 \%$, respectively (Fig. 1).

The full-length cDNA sequence of human ADAMTS-16 was mapped by a BLAST comparison to the BAC clones CTD-2297D10 (GenBank accession no. AC022424) and CTC-485I21 (AC010269) on human chromosome 5p15. ADAMTS-16 appears to consist of 23 exons spanning $180 \mathrm{~kb}$ of genomic DNA (Table 1). Analysis of the genomic region at the $5^{\prime}$ end of ADAMTS-16 indicated that it has a CpG island (AC022424, nt 28 391-27 251; \%GC =66.6; $\mathrm{O} / \mathrm{E}=$ 0.848 ; number of $\mathrm{CpG} 2=112$ ), suggesting that it is expressed in a tissue-specific manner (Fig. 2B). A single transcriptional start site was predicted at the upstream position of $560 \mathrm{bp}$ relative to the translational codon (ATG). The programme PromotorInspector was used to analyse the genomic sequences at the $5^{\prime}$ end of the ADAMTS-16 gene for putative promotor regions. The presence of one strong promotor region of ADAMTS-16 was predicted at nt 27 728-27
478 of AC0022424. Two sp1 sites and one egr-1 site are present in the promotor (Fig. 2C), suggesting that they mediate the expression of ADAMTS-16 during development.

\section{Expression of ADAMTS-16 $\mathrm{mRNA}$ in the ovary}

To determine the tissue-specific expression of ADAMTS-16 in the human, semi-quantitative RT-PCR analysis (semi-Q-RT-PCR) was performed by using a pair of primers corresponding to sequences flanking the first intron. As shown in Fig. 2A, ADAMTS-16 was expressed mainly in adult kidney, pancreas and ovary. We subsequently analysed the expression of the ADAMTS-16 transcript in the UniGene (Build \#184). Expression of ADAMTS-16 was also present in ESTs from brain medulloblastoma, brain amygdala, lung focal fibrosis, lung large cell carcinoma, endometrial adenocarcinoma and retinoblastoma (Wheeler et al., 2003). These results obtained from 
Table 1: Human ADAMTS-16 gene structure

\begin{tabular}{|c|c|c|c|c|c|c|c|}
\hline $\begin{array}{l}\text { Exon } \\
\text { number }\end{array}$ & $\begin{array}{l}\text { Exon } \\
\text { size } \\
\text { (bp) }\end{array}$ & $\begin{array}{l}\text { Position in } \\
\text { cDNA }\end{array}$ & $\begin{array}{l}\text { Intron } \\
\text { size } \\
\text { (bp) }\end{array}$ & $\begin{array}{l}\text { Splice } \\
\text { acceptor }\end{array}$ & Splice donor & $\begin{array}{l}\text { Intron } \\
\text { phase }\end{array}$ & $\begin{array}{l}\text { Ensembl exon } \\
\text { report number }\end{array}$ \\
\hline 2 & 103 & $73-175$ & 5.363 & cgcagGCACC & GGGCGgtaag & 1 & ENSE00001228221 \\
\hline 3 & 326 & $176-501$ & 35.588 & ttcagAATAT & GCTTGgtgag & 0 & ENSE00001228213 \\
\hline 4 & 262 & $502-763$ & 3.746 & tccagTCAGG & GAAATgtatg & 0 & ENSE00001228207 \\
\hline 5 & 200 & $764-963$ & 1.473 & catagACATG & ACATGgtagg & 0 & ENSE00000996102 \\
\hline 8 & 106 & $1208-1313$ & 8.341 & cacagGATTT & CACAAgtaag & 2 & ENSE00000970891 \\
\hline 9 & 138 & $1314-1451$ & 8.823 & catagCTTTG & CTAAGgtagg & 2 & ENSE00000970892 \\
\hline 10 & 154 & $1452-1605$ & 13.542 & ttcagCACCG & AAAAGgcaag & 0 & ENSE00000996101 \\
\hline 11 & 96 & $1606-1701$ & 9.483 & tttagGACAT & ACATGgtaag & 0 & ENSE00001228162 \\
\hline 12 & 149 & $1702-1850$ & 2.497 & tttagTGGTG & CCCAAgtaag & 2 & ENSE00001228154 \\
\hline 13 & 173 & $1851-2023$ & 1.782 & tccagGCCAT & AGAAGgtaaa & 1 & ENSE00001228147 \\
\hline 14 & 131 & $2024-2154$ & 2.051 & ttaagATCAG & GTGAGgtaat & 0 & ENSE00001228138 \\
\hline 20 & 195 & $2992-3186$ & 2.737 & tgcagTGCTC & CCCAGgtagg & 0 & ENSE00001318062 \\
\hline 21 & 225 & $3187-3411$ & 11.405 & tttagTGCTC & CTCAGgtagg & 0 & ENSE00001312646 \\
\hline 22 & 148 & $3412-3559$ & 741 & cacagTGCAC & GAAAGgtgag & 1 & ENSE00001294092 \\
\hline 23 & 116 & $3560-3676$ & & ttcagATGCC & $3^{\prime}$ UTR & & ENSE00001312496 \\
\hline
\end{tabular}

RT-PCR analyses were also supported by microarray expression analyses collected from GNF (Genomics Institute of the Novartis Research Foundation) Expression Atlas Chips U133A, GNF1H and Affy U95 (data not shown, http://symatlas.gnf.org/SymAtlas), confirming that ADAMTS-16 is highly expressed in the ovary, but that it is also expressed to some extent in other tissues.

\section{Hormonal regulation of ADAMTS-16 expression}

We subsequently examined the effects of both FSH and LH on the induction of ADAMTS-16 mRNA expression in both luteinizing granulosa cells and cumulus cells in vitro, collected from patients treated with exogenous gonadotrophins for assisted reproduction. As shown in Fig. 3A, ADAMTS-16 mRNA was predominantly detected in luteinizing granulosa cells with little expression in cumulus cells. A weak but distinct expression pattern was also found in cells of an immortalized granulosa cell line developed from a granulosa cell tumour (KGN, Nishi et al., 2001). By semi-quantitative RT-PCR analysis, the increase in the ADAMTS-16 expression level was detected in the presence of FSH and forskolin (Fig. 3B, lane 3-5), whereas LH (at a concentration of $100 \mathrm{IU} / \mathrm{l}$ ) induced minor changes in the expression level of ADAMTS-16 as compared with FSH (Fig. 3B, lane 1).

In order to further dissect the effects of FSH and LH on the expression of ADAMTS-16 in granulosa, luteinizing granulosa cells were collected from infertile patients treated with exogenous gonadotrophins for assisted reproduction and sorted with FACS based on the concomitant presence of both the FSHR and the LHR. These sorted granulosa cells were then cultured in the presence of recombinant FSH together with anti-LHR-antibodies or in the presence of recombinant LH together with anti-FSHR-antibodies, respectively. As shown in Fig. 3C, under these conditions, the expression level of ADAMTS-16 in granulosa cells cultured in the presence of recombinant FSH and anti-LHR antibody was significantly higher as compared with that of granulosa cells cultured in the presence of recombinant $\mathrm{LH}$ and anti-FSHR-antibodies ( $P=0.02$, Mann-Whitney $U$-test $)$.

\section{$M G$ is a substrate of ADAMTS-16}

Several sequence features of the human ADAMTS-16 are very similar to those of other members of the ADAMTSs family of proteases including the number of cysteine residues (Porter et al., 2005). Thus, this 'trapping' mechanism induces a delayed migration of MG in SDS-PAGE upon incubation with a protease and is considered an experimental evidence of its proteolytic activity, which is different from the cleavage pattern induced by trypsin (Kuno et al., 1999). As shown in Fig. 4A and B, in the presence of ADAMTS-16 produced either by Escherichia coli (Fig. 4A, lane 1 and 2) or by HEK293 (Fig. 4B), migration of $\mathrm{MG}$ on SDS-polyacrylamide gel was altered. Conversion of intact MG to the $90 \mathrm{kDa}$ species was also observed, indicating the formation of MG-ADAMTS-16 complexes, together with proteolysis of MG by ADAMTS-16. MG-ADAMTS-16 complexes were mainly detected in HEK293 cells (Fig. 4B, lane 1). In contrast, high levels of MG could not form high order complexes in the absence of ADAMTS-16 (Fig. 4B, lane 2). In the control experiments, trypsin attack sites were different to those affected by ADAMTS-16 (Fig. 4C). These studies demonstrate that ADAMTS-16 was able to cleave MG.

\section{Discussion}

Various members of the ADAMTS protease family have been implicated in the process of ovulation (Espey et al., 2000; Robker et al., 2000; Madan et al., 2003; Doyle et al., 2004; Mittaz et al., 2004; Shozu et al., 2005; Richards et al., 2005). The liberation of an oocyte from its mature follicle during ovulation is the climax of complex remodelling processes occurring both in the follicular wall and in the cumulus-oocyte complex. This involves remodelling of various components of the ECM through the action of a multitude of proteases. The efficacy of each of these processes results from the equilibrium between the specific components of the ECM and each of the proteases. Both the amount of various components of the ECM and the expression of specific proteases seem to be hormonally regulated during the entire process of follicular development and 
(A)

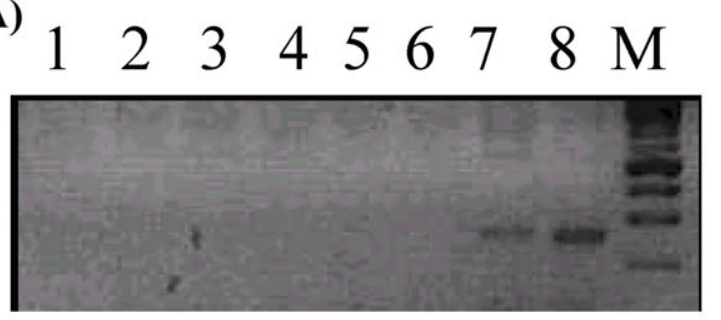

$910111213141516 \mathrm{M}$

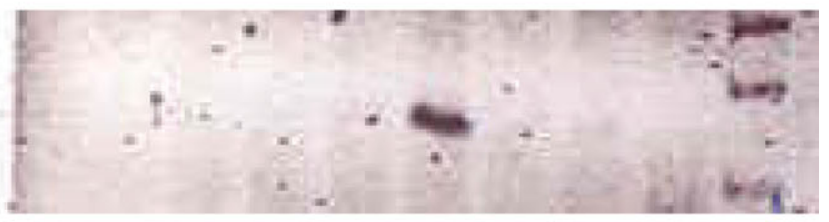

(B)

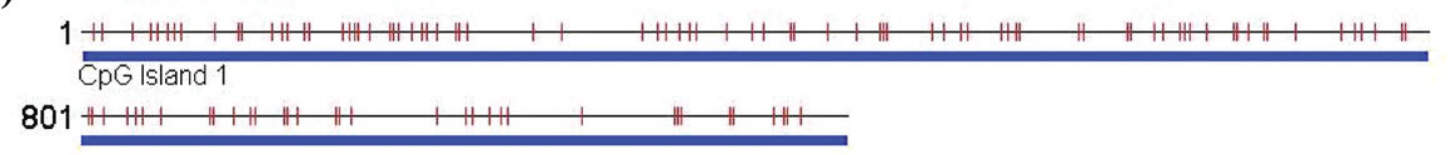

Select lower limits: $\% G C=55$, ObsCpG/ExpCpG $=0.65$, Length $=500$, Distance $=100$ $\mathrm{CpG}$ island 1 start $=1$, end $=1255, \% \mathrm{GC}=66.6, \mathrm{ObsCpG/ExpCpG}=0.848$, Length $=1255$

(C)

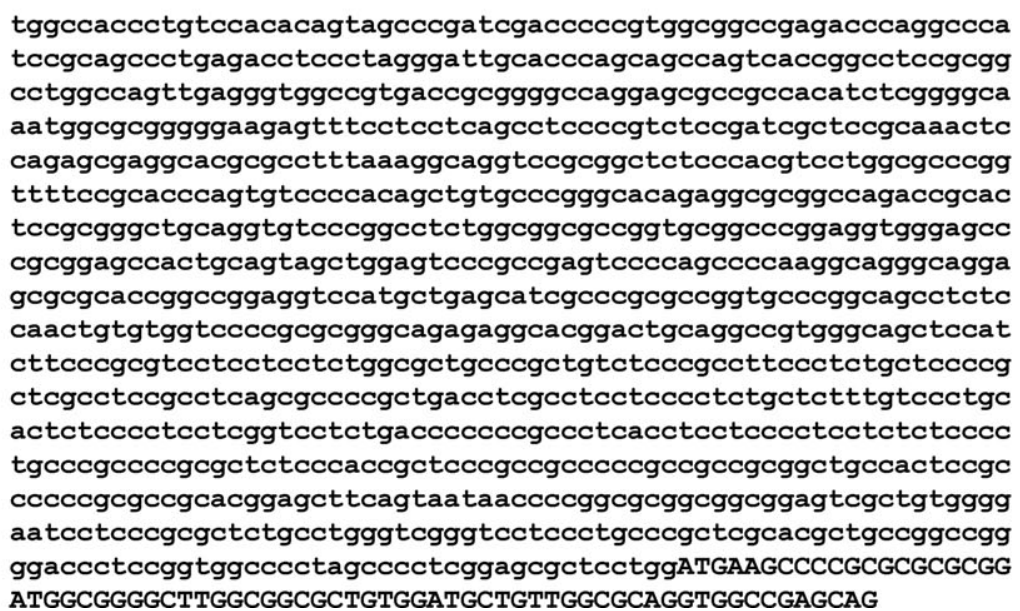

Figure 2: Both the expression level and the distribution of ADAMTS-16 mRNA species vary in different tissues

(A) RT-PCR was performed on a panel of first-strand cDNAs prepared from different human tissues: (1) brain, (2) heart, (3) placenta, (4) lung, (5) liver, (6) smooth muscle, (7) kidney, (8) panceas, (9) spleen, (10) thymus, (11) prostate, (12) testis, (13) ovary, (14) small intestine, (15) colon and (16) peripheral blood leukocytes. (B) Analysis of the genomic region at the $5^{\prime}$ end of ADAMTS-16 using CpGplot. (C) The programme PromoterInspector was used to analyse the genomic sequences at the $5^{\prime}$ end of the ADAMTS-16 gene for putative promotor regions

ovulation. Due to the dependency of the expression and secretion of each component on a particular endocrine signal, which may be conveyed to the tissue both locally and during particular time intervals, the whole process becomes tightly regulated. The stringent control of these processes and the specificity of the various substances involved carries the risk of making ovulation-and with this also the ultimate success of reproduction-crucially dependent on the exact functioning of each individual process. Therefore, the involvement of a large number of substrates and proteases adds an aspect of redundancy to this system (Richards et al., 2005), permitting the ongoing of successful ovulations even in the absence of one of the players (e.g. ADAMTS-1, Mittaz et al., 2004; Shozu et al., 2005).

One of the components of the ECM of the cumulus oophorus, versican, is induced in the granulosa cells under the influence of LH (Russell et al., 2003a) and is a substrate for various members of the ADAMTS protease family, mainly ADAMTS-1 (Russell et al., 2003b). In the PRKO mouse, which fails to ovulate in response to $\mathrm{LH}$, the expression of ADAMTS-1 is significantly reduced (Robker et al., 2000), suggesting an important role of the ADAMTS protease family in the downstream pathway leading to ovulation.
ADAMTS-16 is another member of this family and has not yet been studied in detail. Phylogenetically, it is most related to ADAMTS-18 (Cal et al., 2002) and has been implicated in the pathogenesis of osteoarthritis (Kevorkian et al., 2004). We identified high-expression levels of ADAMTS-16 in the ovary during our search of an ovary-specific gene expression database. The ADAMTS-16 gene was shown to consist of 23 exons spanning $180 \mathrm{~kb}$ of genomic DNA and is located on the human chromosome $5 \mathrm{p} 15$. ADAMTS-16 was expressed only in the parietal granulosa cells of pre-ovulatory follicles, not in the cumulus oophorus, both previously collected from patients treated with exogenous gonadotrophins for assisted reproduction. The increase in ADAMTS-16 expression in luteinizing granulosa cells was only detected in the presence of FSH and forskolin. The change in the expression levels of ADAMTS-16 in sorted granulosa cells provoked by recombinant $\mathrm{LH}$ was significantly lower than those induced by recombinant FSH $(P=0.02$, Fig. $3 \mathrm{C})$. LH considerably reduced ADAMTS-1 expression in human granulosa cells and was modestly repressed after treatment with FSH (Freimann et al., 2005). Most dramatically, forskolin highly suppressed ADAMTS-1 expression as compared with non-treated controls (Freimann et al., 2005). These results 
(A)

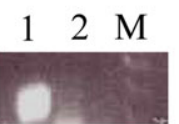

(B)

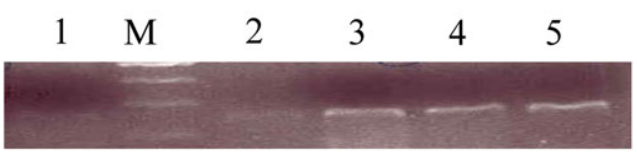

(C)

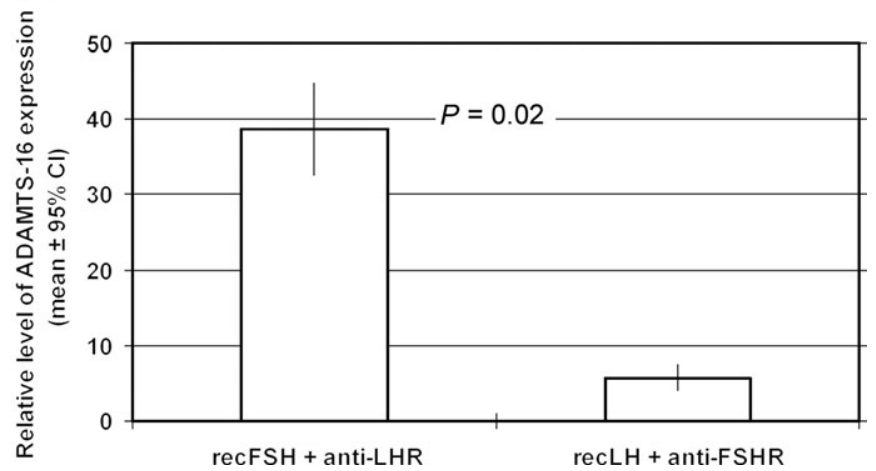

Figure 3: Induction of ADAMTS-16 expression

Representative PCR analysis of ADAMTS-16 expression. (A) PCR was performed on first-strand cDNAs prepared from luteinizing granulosa cells (lane 1) or cells of the cumulus oophorus (lane 2). Semiquantitive-based PCRs were performed. The PCR products obtained from each reaction following 30 cycles were separated on a $1.2 \%$ agarose gel and visualized by serber green I. (B) Human granulosa cells were isolated from patients treated with IVF or ICSI. PCR was performed on first-strand cDNAs prepared from the cells, which after 7 days of culture in DMEM were treated with (1) LH, (3) forskolin, (4) FSH and (5) FSH + Forskolin, (2) served as a control. PCRs (30 cycles) of the housekeeping gene $\beta$-actin were performed in parallel. The amounts of the $\beta$-actin PCR products are equivalent in the different tissues (not shown). (C) Expression of ADAMTS16 mRNA prepared from luteinizing granulosa cells sorted with FACS based upon both FSHR and LHR. The expression of GAPDH mRNA was used as an internal control. The relative level of mRNA expression was determined by real-time PCR and indicated as fold changes over GAPDH expression (ADAMTS16/ GAPDH ratio). Data are compiled from four experiments and presented by their mean values $\pm 95 \%$ confidence intervals

suggest a distinct role of ADAMTS-16 in ovarian function as compared with that of other members of the ADAMTS protease family such as ADAMTS-1. Since the present studies were carried out with parietal granulosa cells aspirated from follicles primed with exogenous gonadotrophins and collected during oocyte pick-up for IVF or ICSI, further studies may be needed to address regulation of this protease in the follicles at earlier stages of development.

MG is a highly conserved proteinase inhibitor present at high concentration levels both in human serum and in ovarian follicular fluid (Gaddy-Kurten et al., 1989; Ireland et al., 2004). For the first time, our results clearly demonstrate that ADAMTS-16 and its variant are able to cleave MG, thereby proving unequivocally that ADAMTS-16 is an active protease. Previously, it was demonstrated that MG is a substrate of ADAMTS-4 and ADAMTS-5 as well (Tortorella et al., 2004). Although the entire spectrum of its cognate substrates in vivo is still unknown, the interaction between ADAMTS-16 and MG may well be physiologically significant, because both are present in high concentrations in the follicular fluid of mature ovarian follicles. MG has been demonstrated to be involved in the regulation of estradiol production by granulosa cells (Ireland et al., 2004). MG interacts with the vascular endothelial growth factor leading to the inactivation of the latter (Bhattarjargee

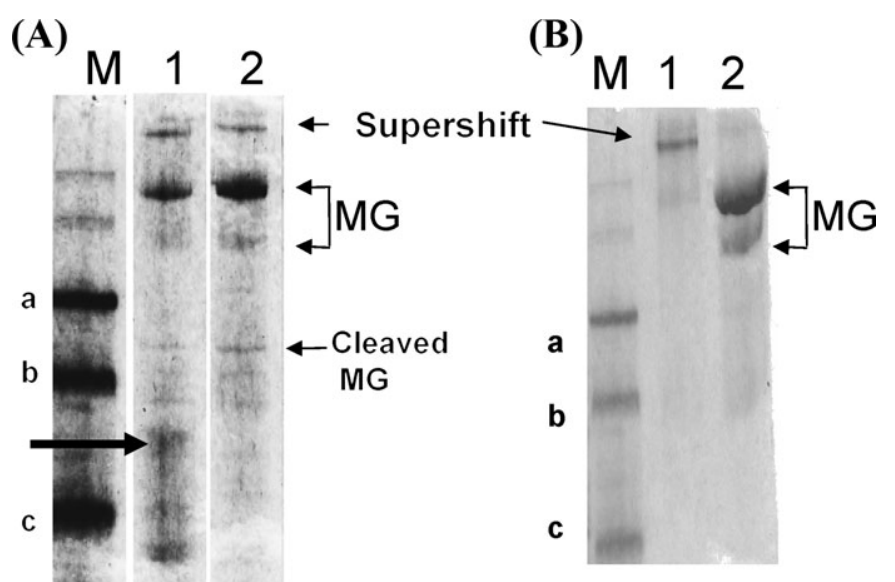

(C)

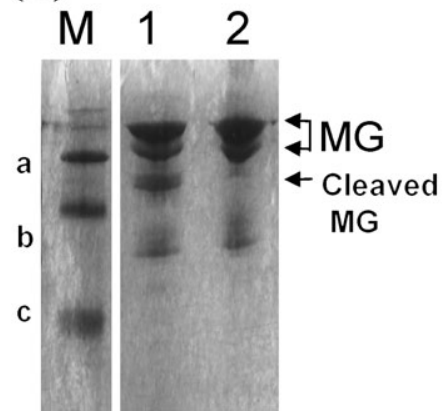

(D)

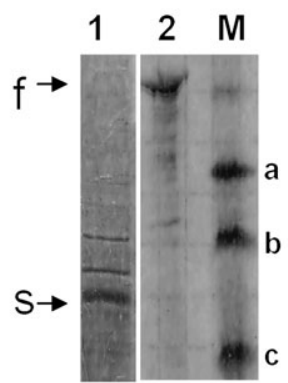

Figure 4: Cleavage of MG by ADAMTS-16

(A) Trapping and cleavage of MG by incubation of ADAMTS-16s (1) and ADAMTS-16 (2) together with MG. In all experiments, equivalent amounts of GST-ADAMTS-16 coupled to GSH beads were used. M indicates a protein marker with a $(103 \mathrm{kD}), \mathrm{b}(77 \mathrm{kD})$ and $\mathrm{c}(50 \mathrm{kD})$. (B) Trapping of MG by incubating with His-ADAMTS-16 (1). (C) Cleavage of MG by trypsin $(0.5 \mu \mathrm{g})$. (D) GST-ADAMTS-16s (1) and GST-ADAMTS-16 (2) produced in E. Coli. f indicates full-length GST-ADAMTS-16 and s indicates GST-ADAMTS-16s

et al., 2000) and is thought to restrict the development of small capillary blood vessels to the thecal layer until final follicular maturation (Gruemmer et al., 2005). ADAMTS-16, which has now been shown to be expressed in the granulosa cell layer of the follicular wall under the influence of FSH, may thus be involved in regulating the local concentration of $\mathrm{MG}$, thereby regulating the development of perifollicular capillaries. These have been demonstrated to be important for follicular development and for the provision of competent oocytes (Van Blerkom et al., 1997). Other members of the ADAMTS family have also been implicated in modulating the formation of intraovarian capillaries, such as ADAMTS-1 (Shozu et al., 2005).

Our studies provide the first evidence that ADAMTS-16 is expressed in parietal granulosa cells of ovarian follicles under the influence of FSH and that it is an active protease of MG, which is present at high concentrations in follicular fluid. We therefore suggest a physiological role of ADAMTS-16 in ovarian follicles, at least during the pre-ovulatory phase.

\section{Acknowledgements}

We are grateful to the Kazusa DNA Research Institute for providing us pblue-script-k-Kiaa2029 plasmid. We are also grateful to NV Organon (Oss, The Netherlands) for providing us with a scientific grant and Dr Sietse Mosselman for his critical review of the manuscript. Part of the study was supported by a grant of the Swiss National Foundation (Nr. 320000-113517/1). GenBank: the accession number for ADAMTS-16-s is DQ266047. 


\section{References}

Bhattachardjee G, Asplin IR, Wu SM, Gawdi G, Pizzo SV. The conformation-dependent interaction of $\alpha_{2}$-macroglobulin with vascular endothelial growth factor. J Biol Chem 2000;275:26806-26811.

Cal S, Obaya AJ, Llamazares M, Garabaya C, Quesada V, Lopez-Otin C. Cloning, expression analysis, and structural characterization of seven novel human ADAMTSs, a family of metalloproteinases with disintegrin and thrombospondin-1 domains. Gene 2002;283:49-62.

Coussens LM, Fingleton B, Matrisian LM. Matrix metalloprotienase inhibitors and cancer: trials and tribulations. Science 2002;295:2387-2392.

De Neubourg D, Robins A, Fishel S, Delbeke L. Quantification of insulin-like growth factor I receptors on granulosa cells with flow cytometry after follicular stimulation. Hum Reprod 1998;13:161-164.

Doyle KM, Russell DL, Sriraman V, Richards JS. Coordinate transcription of the ADAMTS-1 gene by luteinizing hormone and progesterone receptor. Mol Endocrinol 2004;18:2463-2478.

Espey LL, Yoshioka S, Russell DL, Robker RL, Fuji S, Richards JS. Ovarian expression of a disintegrin and metalloproteinase with thrombospondin motifs during ovulation in the gonadotropin-primed immature rat. Biol Reprod 2000;62:1090-1095.

Freimann S, Ben-Ami I, Dantes A, Armon L, Ben Ya'cov-Klein A, Ron-El R, Amsterdam A. Differential expression of genes coding for EGF-like factors and ADAMTS-1 following gonadotropin stimulation in normal and transformed human granulosa cells. Biochem Biophys Res Commun 2005;333:935-943.

Gaddy-Kurten D, Hickey GJ, Fey GH, Gauldie J, Richards JS. Hormonal regulation and tissue-specific localization of $\alpha_{2}$-macroglobulin in rat ovarian follicles and corpora lutea. Endocrinology 1989;125:2985-2995.

Gruemmer R, Klein-Hitpaß L, Neulen J. Regulation of gene expression in endothelial cells: the role of human follicular fluid. J Mol Endocrinol 2005;34:37-46.

Ireland JLH, Jimenez-Krassel F, Winn ME, Burns DS, Ireland JJ. Evidence for autocrine or paracrine roles of $\alpha_{2}$-macroglobulin in regulation of estradiol production by granulosa cells and development of dominant follicles. Endocrinology 2004;145:2784-2794.

Karolchik D, Baertsch R, Diekhans M, Furey TS, Hinrichs A, Lu YT, Roskin KM, Schwartz M, Sugnet CW, Thomas DJ et al. The UCSC Genome Browser Database. Nucleic Acids Res 2003;31:51-54.

Kevorkian L, Young DA, Darrah C, Donell ST, Shepstone L, Porter S, Brockbank SMV, Edwards DR, Parker AE, Clark IM. Expression profiling of metalloproteinases and inhibitors in cartilage. Arthritis Rheum 2004;50: $131-141$

Kikuno R, Nagase T, Nakayama M, Koga H, Okazaki N, Nakajima D, Ohara O. HUGE: a database for human KIAA proteins, a 2004 update integrating HUGEppi and ROUGE. Nucleic Acids Res 2004;32:D502-D504.

Kuno K, Kanada N, Nakashima E, Fujiki F, Ichimura F, Matsushima K. Molecular cloning of a gene encoding a new type of metalloproteinasedisintegrin family protein with thrombospondin motifs as an inflammation associated gene. J Biol Chem 1997;272:556-562.

Kuno K, Terashima Y, Matsushima K. ADAMTS-1 is an active metalloproteinase associated with the extracellular matrix. $J$ Biol Chem 1999;274: $18821-18826$.

Madan P, Bridges PJ, Komar CM, Beristain AG, Rajamahendran R, Fortune JE, MacCalman CD. Expression of messenger RNA for ADAMTS subtypes changes in the periovulatory follicle after the gonadotropin surge and during luteal development and regression in cattle. Biol Reprod 2003;69:1506-1514.
Mittaz L, Russell DL, Wilson T, Brasted M, Tkalcevic J, Salamonsen LA, Hertzog PJ, Pritchard MA. Adamts-1 is essential for the development and function of the urogenitcal system. Biol Reprod 2004;70:1096-1105.

Nishi Y, Yanase T, Mu Y, Oba K, Ichino I, Saito M, Nomura M, Mukasa C, Okabe T, Goto K et al. Establishment and characterization of a steroidogenic human granulosa-like tumor cell line, KGN, that expresses functional follicle-stimulating hormone receptor. Endocrinology 2001;142:437-445.

Porter S, Clark IM, Kevorkian L, Edwards DR. The ADAMTS metalloproteinases. Biochem J 2005;386:15-27.

Porter S, Scott SD, Sassoon EM, Williams MR, Jones JL, Girling AC, Ball RY, Edwards DR. Dysregulated expression of adamalysin-thrombospondin genes in human breast carcinoma. Clin Cancer Res 2004;10:2429-2440.

Richards JS, Hernandez-Gonzalez I, Gonzalez-Robayna I, Teuling E, Lo Y, Boerboom D, Falender AE, Doyle KH, LeBaron RG, Thompson V et al. Regulated expression of ADAMTS family members in follicles and cumulus oocyte complexes: evidence for specific and redundant patterns during ovulation. Biol Reprod 2005;72:1241-1255.

Robker RL, Russell DL, Espey LL, Lydon JP, O’Malley BW, Richards JS Progesterone-regulated genes in the ovulation process: ADAMTS-1 and cathepsin L proteases. Proc Natl Acad Sci USA 2000;97:4689-4694.

Russell DL, Ochsner SA, Hsieh M, Mulders S, Richards JS. Hormone-regulated expression and localization of versican in the rodent ovary. Endocrinology 2003a;144:1020-1031.

Russell DL, Doyle KMH, Ochsner SA, Sandy JD, Richards JS. Processing and localization of ADAMTS-1 and proteolytic cleavage of versican during cumulus matrix expansion and ovulation. J Biol Chem 2003b;278: 42330-42339.

Shindo T, Kurihara H, Kuno K, Yokoyama H, Wada T, Kurihara Y, Imai T, Wang $\mathrm{Y}$, Ogata $\mathrm{M}$, Nishimatsu $\mathrm{H}$ et al. ADAMTS-1: a metalloproteinase-disintegrin essential for normal growth, fertility, and organ morphology and function. J Clin Invest 2000;105:1345-1352.

Shozu M, Minami N, Yokoyama H, Inoue M, Kurihara H, Matsushima K, Kuno K. ADAMTS-1 is involved in normal follicular development, ovulatory process and organization of the medullary vascular network in the ovary. J Mol Endocrinol 2005;35:343-355.

Su AI, Wiltshire T, Batalov S, Lapp H, Ching KA, Block D, Zhang J, Soden R, Hayakawa M, Kreiman G et al. A gene atlas of the mouse and human protein-encoding transcriptomes. Proc Natl Acad Sci USA 2004; 101:6062-6067.

Tortorella MD, Arner EC, Hills R, Easton A, Korte-Sarfaty J, Fok K, Wittwer AJ, Liu R-Q, Malfait A-M. $\alpha_{2}$-macroglobulin is a novel substrate for ADAMTS-4 and ADAMTS-5 and represents an endogenous inhibitor of these enzymes. J Biol Chem 2004;279:17554-17561.

Vázquez F, Hastings G, Ortega MA, Lane TF, Oikemus S, Lombardo M, Iruela-Arispe ML. METH-1, a human ortholog of ADAMTS-1, and METH-2 are members of a new family of proteins with angio-inhibitory activity. J Biol Chem 1999;274:23349-23357.

Van Blerkom J, Antczak M, Schrader R. The developmental potential of the human oocyte is related to the dissolved oxygen content of follicular fluid: association with vascular endothelial growth factor levels and perifollicular blood flow characteristics. Hum Reprod 1997;12:1047-1055.

Wheeler DL, Church DM, Federhen S, Lash AE, Madden TL, Pontius JU, Schuler GD, Schriml LM, Sequeira E, Tatusova TA et al. Database resources of the national center for biotechnology. Nucl Acids Res 2003;31:28-33.

Zheng X, Chung D, Takayama TK, Majerus EM, Sadler JE, Fujikawa K. Structure of von Willebrand-factor-cleaving protease (ADAMTS13), a metalloprotease involved in thrombotic thrombocytopenic purpura. $J$ Biol Chem 2001;276:41059-41063. 